This is the post print version of the article, which has been published in Scandinavian Journal of Psychology . 2019, 60(1), 7-15.

\title{
Development and implementation of a group based mental health intervention
}

for unaccompanied minors

Ferdinand Garoff ${ }^{1,2}$, MA Psychology, PhD Candidate

Samuli Kangaslampi ${ }^{1}$, MA Psychology, PhD Candidate

Kirsi Peltonen ${ }^{1}$, Ph.D, University Researcher

${ }^{1}$ University of Tampere, Finland

Faculty of Social Sciences/Psychology

33014 University of Tampere, Finland

E-mail S.K.: Samuli.Kangaslampi@staff.uta.fi

E-mail K.P.: Kirsi.Peltonen@staff.uta.fi

${ }^{2}$ University of Helsinki, Finland

Faculty of Medicine/Psychology

Haartmaninkatu 3

00014 University of Helsinki, Finland

${ }^{1}$ Ferdinand Garoff (Corresponding Author)

MA, Ph.D student

Faculty of Social Sciences/Psychology

33014 University of Tampere, Finland

Phone: 358 (0) 408454456

email: Ferdinand.garoff@gmail.com

All authors (F.G., S.K., K.P.) have read and approved the final manuscript AND 1) made substantial contributions to the conception or design of the work and the acquisition, analysis, or interpretation of data for the work; AND 2) drafted the work and revised it critically for important 
intellectual content; AND 3) given final approval of the version to be published; AND 4) agree to be accountable for all aspects of the work in ensuring that questions related to the accuracy or integrity of any part of the work are appropriately investigated and resolved.

List of abbreviations:

UM, Unaccompanied Refugee Minors

FGD, Focus Group Discussions

CRIES, Children's Impact of Event Scale

SDQ, Strengths and Difficulties Questionnaire

Acknowledgments

This research was supported by a grant from the Academy of Finland (Grant \# 305590). 


\section{Development and implementation of a group based mental health intervention for unaccompanied minors}

\section{Introduction}

An unaccompanied refugee minor (UM) is a person under the age of 18 who is separated from both parents and is not being cared for by an adult who, by law or custom, has a responsibility to do so, and who is an asylum seeker, recognized refugee or other externally displaced person (UNHCR, 1994). The number of UMs seeking asylum in Finland has increased from 98 in 2007 to a peak of 3,024 in 2015 and then decreasing to 401 in 2016, though still significantly more than in previous years (Finnish Immigration service, 2017).

In Finland, UMs under 16 years of age are accommodated in "group homes" during the asylum application process. UMs who obtain refugee status live in "family group homes", a more permanent arrangement with a similar set-up to the "group homes". In this article we will refer to these as "accommodation units". All UMs in Finland receive social, health care and education services. They are also entitled to legal aid and interpreter services (Finnish Immigration service).

Trauma symptoms and the effects of daily stressors are part of everyday life in the accommodation units, but the staff have limited tools to tackle them. On the other hand, UMs often lack motivation and ability to engage with external treatment. This article describes the test for the first level of a stepped model of trauma care, a group intervention developed to address the mental health needs of UMs in the setting where they live. 


\section{Mental Health Challenges of Unaccompanied Minors}

Separation from their family and support networks exposes UMs to multiple losses and various challenges that make them vulnerable to distress and mental health problems (Clark-Kazak, 2012; Derluyn \& Broekaert, 2008). A study in Belgium (Derluyn, Broekaert, \& Schuyten, 2008) found that UMs were five times more likely, than accompanied refugee minors, to experience severe symptoms of anxiety, depression and posttraumatic stress. Similar results with regard to post-traumatic stress disorder (PTSD) were found among UMs in Netherlands and Belgium (Bean, Derluyn, EurelingsBontekoe, Broekaert, \& Spinhoven, 2006). A study in Norway (Jensen, Skårdalsmo, \& Fjermestad, 2014) found that there was little change in the average level of mental health symptoms among unaccompanied minors from 6 months to 2 years after arrival. However, the trajectories were quite varied among the respondents, some recovering, others reporting increased symptom levels or maintaining a high level of symptoms.

Daily stressors have been found to mediate the impact of war trauma on psychological well-being among resettled adults (Nickerson, Steel, Bryant, Brooks, \& Silove, 2010) and war-affected youth (Newnham, Pearson, Stein, \& Betancourt, 2015). Both war trauma and post-migration stressors influence mental health, and the post-migration environment may either foster or impend recovery from losses and traumatic experiences of war (Miller \& Rasmussen, 2016). Socioeconomic challenges, social isolation and discrimination, as well as immigration and refugee policies have been found to impact the mental health of refugees and asylum seekers. In addition, the possibilities for developing life-skills, as well as access to nurturing relationships and education may be limited for children and adolescents forced to migrate, and this may constitute a loss of future livelihoods and opportunities (ISTSS, 2017). Some of these daily stressors among UMs were also found in an earlier study in Finland (Sourander, 1998). UMs expressed a concern for the well-being of their parents and worries about the asylum application process. They also felt that Finnish staff, responsible for their well-being, were 
remote, but many expressed a wish to discuss their situation and problems with adults they could trust. However, the concept of resilience has been established in order to capture the resources to overcome adversity even in very stressful situations (Panter-Brick, 2014; Ungar \& Liebenberg, 2011).

\section{Mental Health Interventions}

Generally, psychotherapy is an effective form of treatment, and the results obtained among ethnic minorities do not seem to be different from those of other groups (Miranda, Bernal, Lau, Kohn, Hwang, \& la Fromboise, 2005; Renner, 2009). A recent review (Slobodin \& de Jong, 2015) found that culturally adapted, standardized protocols of trauma-focused treatments based on Cognitive-Behavioral Therapy (CBT) could be suitable and effective for traumatized refugees. Trauma-focused CBT interventions are also recommended in international guidelines for children and adolescents with posttraumatic symptoms (NICE, 2005; Duodecim, 2017) and the effects of treatment have been found to be maintained over time (Jensen, Holt, \& Ormhaug, 2017). Many youths have negative expectations about coming to therapy, but those who complete Trauma-focused CBT treatment tend to view working with their trauma stories and learning skills for reducing stress the most helpful interventions (Dittmann \& Jensen, 2014). However, trauma-focused methods are not widespread or carefully implemented, especially in the case of children and people with multiple and severe traumas (Cahill, Foa, Hembree, Marshall, \& Nacash, 2006). In a Dutch sample of UMs, almost half reported that their need for mental health care was unmet (Bean, Eurelings-Bontekoe, Mooijaart, \& Spinhoven, 2006). It seems that there is a mismatch between UMs' mental health needs and the provided services (Pottie, et al. 2011). For instance, Michelson and Sclare (2009) found that unaccompanied minors had a higher rate of missed appointments at the clinic and attended fewer total sessions. Some UMs may also consider PTSD symptoms to be the inevitable consequence of their experiences and may be reluctant to discuss their past experiences, particularly if accommodation unit placements are unstable and their legal status 
uncertain (Sanchez-Cao, Kramer, \& Hodes, 2012). In Finland, typical mental health services for UMs include child and adolescent psychiatric services, but access and their readiness and ability to address the needs of UMs vary greatly. In addition, trauma-focused treatment is seldom available and treatment processes are sometimes discontinued due to lack of engagement of the UMs or constraints by the service provider (personal communication by accommodation unit staff). UMs often have a negative view of mental health service providers and may deny the need for services. They also often express a lack of trust and therefore do not disclose their problems, even if referred (Majumder, O’Reilly, Karim, \& Vostanis, 2014).

In a scoping review of psychotherapeutic interventions with UMs (Demazure, Gaultier, \& Pinsault, 2017) found that evidence is still scarce in this group. Only one RCT was identified. In this study (Ehntholt, Smith, \& Yule, 2005), the Teaching Recovery Techniques (TRT) prevention program was implemented in a school setting, clinically modest reduction in posttraumatic stress symptoms were found following the intervention, however gains were not maintained among those that participated in the 2-month followup. A more recent study from Sweden, implemented the TRT program in a community setting among UMs with PTSD symptoms and suicidal ideation (Sarkadi, et al. 2017). The TRT program enabled normalization of the trauma reactions, offered social support and provided tools for coping with intrusive thoughts and memories, regulating arousal and managing avoidance.

\section{The Current Study}

In order to address the gap between mental health needs of UMs and the availability of services in Finland, a stepped model of trauma care was developed. The model includes: 1) A group based intervention focused on stabilizing and preventing mental health problems. 2) An individual traumafocused intervention for those that are found to have significant posttraumatic symptoms in screening at the end of step 1, and are willing to participate in individual treatment. The model is based on the phase-based approach of trauma care (Herman, 1992). The group intervention corresponds to the 
focused non-specialized support, and the individual intervention to specialized services, as described in the Inter-Agency Standing Committee Guidelines for Mental Health and Psychosocial Support (IASC, 2007), the intervention may also address some of the basic safety needs of the UMs.

This article describes the first level of the stepped model, the group intervention developed for UMs, which was implemented at three accommodation units in Finland (co-) facilitated by the staff that interact with the UMs on a daily basis.

\section{Development of the Intervention}

The group intervention was developed by the research team and two mental health professionals with extensive experience working with severely traumatized refugees at the Centre for Torture Survivors in Finland. In the development process, staff of various organizations with experience of working with refugees or other traumatized groups were interviewed in order to screen the good practices in the field. These organizations included Swedish Red Cross, the Finnish Association for Mental Health, the Center for Victims of Torture and the Centre for Trauma Therapy and Trauma Education in Finland. The materials shared by interviewed experts were reviewed. The final model was developed by 1) adapting existing materials shared by other organizations to the needs of UMs, 2) adding elements and exercises relevant to the situation of UMs not available in earlier models and 3) adjusting contents for implementation by non-mental health professionals. In addition, contents were revised and further adjusted to the target group during the process. The TRT model was also considered, but regarded as too trauma-focused for the first step of the intervention model, particularly as the intervention under development was to be implemented by non-mental health professionals.

\section{Implementation}

The group intervention was implemented in two large population centers in Finland (Helsinki and Tampere) from March 2017 to May 2018 in collaboration with the three accommodation units: units (a) 
and (b) for UMs with refugee status and unit (c) for asylum seekers. The group intervention was preceded by an information session for the youth and staff, as well as motivational discussions by accommodation unit staff with the UMs. The groups were intended to be organized as closed groups with 4-8 participants, including all UAMs living in the unit, but smaller groups of three individuals and even two individual processes were started as a result of the particular dynamics at each unit.

All available staff members were offered a one-day training covering topics including: the present study, trauma and its consequences, supporting UMs in daily life and stress management. Staff members willing to facilitate the groups were offered additional two-day training covering topics including: a review of the group model, reactions and needs of UMs, group dynamics, working with the body, coping resources and identity.

The first three groups in 2017 were facilitated by a mental health professional and two trained staff members, supported by the necessary interpreters. The fourth group (2018) was facilitated by a staff member who had facilitated the group in 2017 together with another trained staff member with no previous facilitation experience of this group model. The two individual processes started in 2018 were facilitated by staff that had facilitated the groups in 2017. Members of the research team participated in planning of these groups including contents, materials and group composition. The research team also provided consultation throughout the process upon request, including for the decision to discontinue one of the individual processes that had been started.

The group intervention included ten weekly 90 minute sessions. All sessions except the first and last followed the general structure of i) getting together, including snacks and drinks, ii) a body-oriented relaxation and stabilization exercise, iii) an exercise and discussion about the topic of the session, iv) closing with a relaxation exercise and v) final words or showing how you feel with picture cards. An overview of the session outline including examples of activities is provided in Table 1. below. 
Table 1. Session outline with examples of activities

\begin{tabular}{|c|c|c|}
\hline Session & Topic & Activities \\
\hline
\end{tabular}

\begin{tabular}{|c|c|c|}
\hline 0 & Information session & Presentation of the study, questions, informed consent \\
\hline 1 & Group formation & $\begin{array}{l}\text { Group rules, team building, review of session contents, } \\
\text { practicing grounding exercises }\end{array}$ \\
\hline 2 & Psycho-education & Psycho-education, completing self-report questionnaires \\
\hline 3 & Well-being & $\begin{array}{l}\text { Brief ethnographic interview (Hubbard, 2012) about well-being, } \\
\text { identifying important themes }\end{array}$ \\
\hline
\end{tabular}

4-7 Topics identified by Psycho-education, exercises and discussions linked to the various participants

topics (e.g. sleep, pain, intimate relationships, emotions, anger)

8 Coping resources Sociogram, coping resource exercise

9 Future Tree of the future exercise

10 Closing party Informal party, composing a letter to future groups, completing self-report questionnaires

\section{Research Questions}

1) Intervention implementation. Is the first level of the stepped care model, the group based intervention, practical and relevant in the 'real world' context of the accommodation units? 
2) Mental Health and Behavior. Does the group based intervention address the mental health needs and improve daily functioning of UMs? 


\section{Method}

\section{Participants}

All UMs living in the participating accommodation units, units (a) and (b) for UMs with residency permits and unit (c) for asylum seekers, in 2017-2018 were offered a chance to participate in the study. The groups had different trajectories. The group (a) started with five participants and increased to seven (unit (a) 2017, n=7). Two UMs, who did not want to participate in the group at unit (a) in 2017, joined a second group at the same unit in 2018 together with one newcomers (unit (a) 2018, n=3). At unit (b) the groups started with five participants, but one of them reluctantly drop-out due to an all-important hobby and school work (unit (b), n=4). At unit (c) one of the leadership figures among the UMs rejected the group intervention in the information meeting, which may explain why all but one of the UMs chose not to participate. However, the process was started with the one remaining UM who was joined by two newcomers in the third session (unit (c), n=3) and they all completed the group process. In addition to the groups, two individual processes were started in 2018 and run by trained staff members who had facilitated the group in 2017. The reason for these individual processes was the apparent need for mental health support for the particular youths, but a group process was not possible at unit (c) as other UMs had already participated in the process and at unit (a) the UM offered an individual process had been in conflict with other UMs participating in the group. The individual process at unit (c) was discontinued as the participating UM expressed discomfort thinking about the past and current stressors. Additional consideration and support was instead provided by the staff member in daily life, with the possibility of later referral. The individual process at unit (a) had 60 minute sessions and was completed as planned.

\section{Measures}

\section{Evaluation of the Implementation}


For research question 1, about the practicality and relevance of the implemented group intervention, data was collected in two ways. 1) Focus Group Discussions (FGD; Krueger, 2002) were conducted after the group based intervention by the researchers with staff of each of the accommodation units (five interviews, $n=9$ ) and mental health professionals ( 1 interview, $n=2$ ) who had been responsible for facilitating the groups or individual processes. FGDs were also conducted with 3 UMs that had participated in the group at (a) in 2017 (two interviews, n=3) and the UM who completed the individual process in $2018(n=1)$. The FGDs consisted of collecting Most Significant Change (MSC; Davies \& Dart, 2005) stories and a semi-structured interview. Audio recordings of the FGDs with facilitators were made, supplemented by notes by researchers. Only one of the UMs was comfortable with the audio recording of the FGD, but notes were made by researchers for all FGDs with UMs.

Group facilitators completed a 2) session questionnaire after each session to record participant attendance, themes, methodologies, problems that arose and important moments and observations. Recommendations with regard to research question 1. presented in this paper were compiled by the first author based on notes and recordings of the FGDs and a review of the session questionnaires. Recommendations were presented to the research group, the group facilitators and staff of the accommodation units with an opportunity to comment.

\section{Mental Health and Behavior Outcomes}

For research question 2, about the mental health and functioning outcomes of the intervention, both qualitative and quantitative data was collected. Brief Ethnographic Interviewing (Hubbard, 2012) was used to explore aspects of well-being among UMs at the accommodation units. Brief semi-structured interviews were conducted framed around three questions relating to a specific, undisclosed youth or child in the accommodation unit: 1) "Think of a youth who is doing well, how can you tell he or she is doing well?", 2) "Think of a youth who has problems, what kind of problems do they have?", and 3) 
"What would help a person recover from this kind of problems?". The interviews were conducted by the first and third author with groups of accommodation unit staff prior to starting the group intervention. Youths were interviewed by facilitators during the third group session and identified themes were then used to inform the choice of themes for group sessions four to seven. Responses were collected in written format and input into Excel and transferred to SPSS for analysis. The first author then sorted the responses for staff members and youth separately into 29 general domains that emerged from the dataset, the classification was further reviewed for accuracy by the third author.

\section{Self-report questionnaires on posttraumatic stress symptoms and resilience were collected from UMs}

as pre- and posttest measures before (T1) and after (T2) the group intervention. All self-report questionnaires were translated by official translators into the mother tongue of the participants, then back-translated by other translators into Finnish and reviewed for accuracy by the research team. It was not possible within the scope of the study to pilot the translations separately. Also, staff responsible for the participating youths completed questionnaires relating to the psychological distress of their youths at $\mathrm{T} 1$ and $\mathrm{T} 2$. The measures and analyses used are described below.

Posttraumatic Stress Disorder (self-rated). The 13-item Children's Impact of Event Scale (CRIES; Smith, Perrin, Dyregrov, \& Yule, 2003) based on the DSM-IV (American Psychiatric Association, 2000) covers three core dimensions of PTSD: re-experiencing (four items), avoidance (four items) and hyper-arousal (five items) symptoms. Participants indicated on a 4-point scale how often they had had each symptom during the last two weeks ( $0=$ not at all, $1=$ rarely, $3=$ sometimes, $5=$ often $)$. Because participants in our study have experienced multiple traumatic events, they were instructed to think about the most stressful event when completing the questionnaire. The total score includes all items. A sum-score of 17 or higher on the intrusion and avoidance sub-scales is recommended as a cut-off for clinically significant 
levels of posttraumatic stress (Perrin, Meiser-Stedman, \& Smith, 2005) and used in this study. Cronbach's alphas in this study were .89 (T1), and .84 (T2).

Resilience (self-rated). A questionnaire measuring individual resilience among war traumatized children was first developed in another ongoing study in Finland (Kangaslampi, Garoff, \& Peltonen, 2015) and its psychometric properties of are still under evaluation. It was used after considering a well validated Child and Youth Resilience Measure (CYRM; Ungar \& Liebenberg, 2011), but finding some difficult items for UMs in it. The questionnaire consists of ten items measuring the positive resources of children/adolescents (e.g., "I have a skill in which I am particularly good at"; "I feel that I am important to someone"). Participants evaluated on a 3-point scale how well the description fitted them $(0=$ not at all, 1 = somewhat, 2 = yes, fit well). Cronbach's alphas in this study were .73 (T1), and .66 (T2).

Psychological distress (staff-rated). The Strengths and Difficulties Questionnaire (SDQ; Goodman, 1997) was used to assess the emotional, behavioral, and relational problems, hyperactivity, and pro-social behavior of the participants. Each of the five dimension consists of five items rated on a 3-point scale on how well the description fit the participants $(0=$ not at all, $1=$ somewhat, $2=y e s$, fits well $)$. The questionnaire for parents was completed by staff members who were responsible for the participating UMs. SDQ total difficulties scores, that exclude pro-social behavior, were banded as suggested by Goodman (Goodman, 1997). Cronbach's alphas in this study were .81 (T1) and .75 (T2).

\section{Statistical Analysis}

Quantitative data was available from 13 participants. Demographic details were available for 12 participants. There were two types of missing data. First, there were five individual missing data points (out of 1248 data points, $0.40 \%$ missing), representing single unanswered questions in otherwise completed pretest measures of posttraumatic stress symptoms. These missing values were replaced by 
the mode answer for that measure for the same participant. Second, posttest measures were missing in part for one participant. The answers of another participant were considered as outliers due to the participant having denied any symptoms or problems in both self-report measures; according to accommodation unit staff this assessment was inaccurate. These participants were excluded from analyses for the corresponding outcomes in a pairwise manner. According to $t$-tests, there were no significant differences between those providing complete data and those who had missing data in age or mental health variables at pretest. Dependent samples $t$-tests were carried out to examine changes in the mental health variables from pretest to posttest, with $\alpha=.05,95 \%$ confidence intervals for changes from pretest to posttest were constructed, and Hedges's gav reported as effect size measure. All analyses were carried out using R version 3.2.4 (R Core Team, 2016).

\section{Ethical Considerations}

The Ethics Committee of the Tampere region provided the ethical review and permission to conduct the study was obtained from the Helsinki Deaconess Institute and the City of Tampere. Research involving UMs raises specific ethical issues due to their vulnerable situation (Vervliet, Rousseau, Broekaert, \& Derluyn, 2015). The participants in the study were repeatedly provided information about the purpose and stages of the data collection, as well as the possibility of discontinuing participation at any time, by the research team, facilitators and the staff members. The staff members, facilitators and UMs provided informed written consent at baseline. Some of the boundary issues between research priorities and needs of UMs (Vervliet, Rousseau, Broekaert, \& Derluyn, 2015) could be avoided as the research was implemented in the daily life settings of the UMs by staff familiar with their situation and with access to other service providers throughout the process, including mental health referrals, if necessary. 


\section{Results}

\section{Intervention Implementation}

Altogether, 14 UMs completed the group process in 2017, an additional three UMs completed a group process in 2018 and one UM completed an individual process for a total $\mathrm{N}=18$. The participants ranged from 9 to 17 years old $(M=15.08, S D=2.28)$. Two participants were girls, while all others were boys. The participants were mainly of Afghan (7/12) and Iraqi (2/12) nationalities. The time of their arrival in Finland ranged from 42 months to less than two months before the start of the group intervention, though most (7/12) had arrived during 2015. The 3 UMs that participated in the (c) group were asylum seekers; all others had received temporary residency permits. Most of the UMs participating in the study have previously been referred to youth psychiatric services, some having an ongoing medication. Some youths have received counseling, but it has petered out or been discontinued by the UMs (personal communication by staff members).

Due to challenges in group formation at unit (c), described above, questionnaire data was not available from this group as the only one participant that completed the group was present at the second session. One youth did not want to complete the questionnaires in the 2018 group. The groups in 2017 at units (b) and (c) started later than at unit (a) and ran for nine sessions, as summer vacations and Ramadan constrained their length. The group at unit (a) completed the entire 10 sessions. The group and individual process in 2018 at unit (a) both ran for the full 10 sessions. The individual process started in 2018 at unit (b) was discontinued after the first session. However, even with the groups that only included 9 sessions the phase-based process could be maintained, with some adjustment to the final sessions. Once the group dynamics had settled down by session 3 (this was mainly an issue at unit (c)) all but one UM completed a 9 or 10 session group process. One UM completed a 10 session individual process and another discontinued it after session one. 
Based on the symptom measures and facilitator FGDs, the second level of the stepped model, the individual trauma focused intervention was offered to all participants, with additional efforts to enlist particularly affected individuals. Only one of them was willing to start the individual treatment immediately after the group intervention, but three additional treatments were started with some delay after active follow-up by staff.

\section{Most Significant Change Stories}

The general perception among group facilitators was that that the youths settled down in the groups, which was also reflected in daily interactions at the accommodation units. "One or two of the boys when we started they were very much scapegraces making a mess of things, being chaotic. And the last time I saw them they came in and they were straighter, like they had a different habitus". The facilitators also noticed that trust between participating youths and staff members was increased during the intervention. "I think the group came at a time that... we didn't know the youth so well and they hadn't known us. So the group functioned to ... through it, the trust slowly grew both ways and we learned to know each other better." This perception was echoed by participating UMs. "It was fun to sit and eat with friends. ... I would recommend participating in the group for others... There was trust ... we could talk with adults about important things... This is not like when you are joking with friends."

\section{Focus Group Discussions and Session Questionnaires: Recommendations}

The following section is based on the FGDs with facilitators and UMs, as well as the session questionnaires. Key recommendations, following the structure of the FGDs and summarized by the researchers, are outlined below.

Group processes: In the accommodation units inclusiveness was felt to be more important than following the recommendation (Ehntholt, Smith, \& Yule, 2005) to implement groups with youths of 
same country and ethnic background. On the other hand, one of the UMs, who had quite severe symptoms, was offered individual sessions in 2018 rather than being included in the group at unit (a), this arrangement was felt to be more comfortable by the staff and all the UMs. Contrary to recommendations (Ehntholt, Smith, \& Yule, 2005), one of the groups consisted of asylum seeking UMs some arriving very recently in Finland. Despite their novel and uncertain situation facilitators still felt they benefitted from the process.

The accommodation unit staff had to work hard to motivate the UMs to participate in the beginning, though this became easier as the group had become a weekly routine. Motivating the youth to participate, as well as addressing unrealistic expectations, is important in order to build trust between participants, facilitators and in the group process. This includes repeatedly returning to the purpose of the study (Vervliet, Rousseau, Broekaert, \& Derluyn, 2015).

Structure and participation: 9 or 10 group sessions of 90 minutes worked well in the accommodation unit setting, though60 minutes sessions seemed to be sufficient for individual sessions. A small group size, three to five participants, was felt to be functional when working with groups of UMs that needed several interpreters. This allowed for more direct interaction with facilitators and addressing individual UMs needs, e.g. one of the groups was implemented with three UMs, three interpreters and two facilitators, nevertheless the process was felt to be quite intimate and the UMs provided each other social support and became friends as they could interact through the interpreters.

Themes and methods: In the FGDs all interviewed UMs expressed that important issues had been addressed in both the individual and group the processes. Some of the themes are quite sensitive and may trigger strong emotions, as evidenced by the one drop-out in 2018 where just mentioning possible hardships made the UM uncomfortable. 
Activities also need to be adapted to the participants and facilitators, e.g. in some of the groups organized in 2017, the body-oriented exercises met with limited success as the youths felt the exercises to be awkward or "crazy", but the older participants in 2018 were quite comfortable with the relaxation exercises.

More important than the particular themes and activities may be the trust building taking place between staff and participating UMs, and between the UMs themselves. Increased trust was mentioned in all the FGDs. According to UMs trust was facilitated by a respectful, patient, polite approach by staff and the rules and structure of the group. After the process, they felt that it was easier to approach the staff and they felt they could understand each other's culture better. It is important to note that at this stage, many of the UMs had already known the staff members and each other for more than a year, sometimes for years, but many times the UMs had held staff at arm's length and did not know much about the inner lives of each other. Accommodation unit staff that facilitated the processes also felt that it helped build and clarify the relationships with the UMs and improved relationships between the UMs.

Facilitation and support: As recommended (Ehntholt, Smith, \& Yule, 2005), all groups had co-facilitators, but the individual processes had only one facilitator. After the group processes staff felt empowered to facilitate similar groups independently. In 2018 group and individual processes were started in units (a) and (b), with support in the planning process by the research team and opportunities for consultations, mainly used by those facilitating the individual processes. The accommodation unit (c) was closed in 2017. When accommodation unit staff start to facilitate these processes independently it is important to adapt and go through the contents and activities to fit the particular group of UMs and for the staff members to become comfortable with the materials, e.g. find their own words, think through the activities and mentally prepare for the sessions. Therefore, it is important to set aside enough time, e.g. 60 minutes, every week for preparation with co-facilitators, and if challenging moments arise during the 
process to have the possibility to consult mental health professionals, in addition to collegial support. Also, the importance of having a good interpreter that the UMs are comfortable with and who understands the group setting was emphasized in all the FGDs with facilitators.

Research methods: Completing the self-rated questionnaires was challenging in some of the groups, particularly at baseline. The questions were difficult for some of the UMs to understand and the steps on the Likert-scale were also hard to differentiate for some UMs, however this could be mitigated with explanations and with the help of the interpreters. In addition, for some of the UMs the Posttraumatic Stress Disorder questions were distressing and for others completing the questionnaire in a group setting created social anxiety. This may have influenced individual responses. At unit (a) endline questionnaires were completed outside the group setting with a staff member and interpreter available. This worked better as it afforded opportunity for questions and clarifications.

\section{Mental Health and Behavior}

\section{Brief Ethnographic Interviewing}

63 separate responses from 11 UMs and 737 responses from 35 staff members were recorded. The number of separate responses per question and participant ranged from 1 to 15 . Responses of the staff were reviewed and classified into 29 domains related to the categories of doing well, problems and support. Table 2 below summarizes the main domains identified by accommodation unit staff to identify UMs that are doing well, those that are having problems and support strategies.

Table 2. Staff-identified domains of well-being, problems and support among UMs ${ }^{A}$

\begin{tabular}{lll}
\hline \hline Doing well & Problems & Support
\end{tabular}

\begin{tabular}{lll}
\hline Sociability, participation ("is in & Emotional regulation, impulse & Services ("medication", \\
contact and social", "he has & control ("gets agitated easily", & "collaboration with child
\end{tabular}


friends")

\section{Communication, self-expression}

("shows his emotions", "talks

about things that are important

to him") "self-harm")

Sociability, participation

("withdrawn", "lacks empathy")

"getting attention from adults")

Activities ("a good and

interesting hobby", "doing many

things together with the

youths")

Communication, self-expression

("calm dialogue", "listening")

\footnotetext{
${ }^{\mathrm{A}}$ Main domains represent more than $10 \%$ of responses in each category. Example responses for each category are in brackets.
}

Unfortunately, the UMs' interpreted and responded to the questions in the Brief Ethnographic Interviewing in different ways and the responses were not collected and translated systematically by facilitators. However, many of the available UMs' responses also related to sociability and participation, e.g.: "helps others" (doing well), "Ioneliness when I arrived" or "finding a friend is really difficult" (problems), and "I make surprises for him" (support).

\section{Changes in Mental Health Variables and Screening}

Table 3 presents the levels of the mental health variables at pretest and posttest and the results of $t$ tests for significance of changes from pretest to posttest. 
Table 3. Paired-samples $t$ tests for changes in mental health variables from pretest to posttest.

\begin{tabular}{|c|c|c|c|c|c|c|c|c|}
\hline \multirow[b]{2}{*}{ Measure } & \multicolumn{2}{|c|}{ Pretest } & \multicolumn{2}{|c|}{ Posttest } & \multirow[b]{2}{*}{$t$} & \multirow[b]{2}{*}{$d f$} & \multirow[b]{2}{*}{$p$} & \multirow[b]{2}{*}{$95 \% \mathrm{Cl}_{\text {diff }}$} \\
\hline & $M$ & SD & $M$ & SD & & & & \\
\hline CRIES & 32.90 & 9.50 & 36.80 & 10.89 & 1.30 & 9 & .23 & {$[-2.88,10.68]$} \\
\hline CYRM & 12.91 & 3.30 & 12.64 & 3.17 & 0.31 & 10 & .76 & {$[-1.70,2.25]$} \\
\hline SDQ total difficulties & 14.42 & 5.85 & 14.75 & 5.28 & 0.23 & 11 & .82 & {$[-2.80,3.46]$} \\
\hline
\end{tabular}

According to dependent samples $t$-tests, there were no significant changes in posttraumatic stress symptoms from pretest $(M=32.90, S D=9.50)$ to posttest $(M=36.80, S D=10.89), t(9)=1.30, p=.23$, $95 \% \mathrm{Cl}_{\text {diff }}[-2.88,10.68], g_{a v}=0.35$; in resilience from pretest $(M=12.91, S D=3.30)$ to posttest $(M=$ $12.64, S D=3.17), t(10)=0.31, p=.76,95 \% \mathrm{Cl}_{\text {diff }}[-1.70,2.25], g_{a v}=.0 .08 ;$ nor in total difficulties from pretest $(M=14.42, S D=5.85)$ to posttest $\left(M=14.75, S D=5.28, t(11)=0.23, p=.82,95 \% \mathrm{Cl}_{\text {diff }}[-2.80\right.$, 3.46], $g_{a v}=0.06$.

At pre-test $73 \%(8 / 11)$ of youths and at post-test $80 \%$ (8/10) exceeded the CRIES cut-off for probable PTSD. For the SDQ, at pretest $38 \%(5 / 13)$ of youths scored in the abnormal range and $15 \%(2 / 13)$ in the borderline range and at posttest $33 \%(4 / 12)$ of youths scored in the abnormal range and $17 \%(2 / 12)$ youths in the borderline range.

\section{Discussion}

Availability of trauma treatment that suits the needs of asylum seeking or refugee adolescents has been found to be insufficient. Lack of trust is also a major reason for refusal or discontinuation of psychiatric services among UMs (Majumder, O’Reilly, Karim, \& Vostanis, 2014), and experience has shown that 
building trust in adults in the host country is a long process for them. Many of the UMs that participated in this study had previously been referred to psychiatric services, but apart from medication, services had largely been discontinued, frequently as the UMs had not been willing or able to share their difficulties with services providers.

Cloitre (2015) has called for development of novel, alternative interventions. In this study we have developed a stepped model where mental healthcare comes as close as possible to the everyday contexts of UMs. The first level trauma care groups aimed to provide psycho-education and stabilization in the accommodation units in order to prepare participants for the second level individual trauma focused treatment (Herman, 1992). In addition, the groups served as a means of integrating a traumainformed approach into the daily environments of UMs.

Multicomponent therapy models have implied that sequencing is necessary for PTSD recovery in those with complex forms of PTSD (Cloitre, Courtois, Charuvastra, Carapezza, Stolbach, \& Green, 2011; De Jongh \& Broeke, 2014). In contrast, some researchers have dismissed the importance of additions to trauma-focused therapies, and proposed that delay in confronting traumatic memories with add-on interventions reduces the efficacy of the treatments by encouraging avoidance of the trauma (Van Minnen, Harned, Zoellner, \& Mills, 2012).

In this study there was no indication in the quantitative data that the stabilizing group intervention significantly impacted mental health symptoms among UMs. However, the qualitative reports from both facilitators and UMs showed that, after some initial uncertainty, participants talked about important issues and that this sharing resulted in increased trust and confidence between staff and participants as well as between participating UMs. For many of the participants, the group intervention was the first experience in sharing their thoughts and emotions in the host country. Successful trust building by adults in the daily environment may also promote help seeking behavior in the long run. This is 
evidenced by the three cases in this study, where youth that initially declined individual trauma care later asked it themselves.

Sociability and participation emerged as the main factors indicating well-being of UMs in the Brief Ethnographic Interviewing. In turn, negative social interactions and lack of participation, as well as the problems with emotional regulation and impulse control, were the main indicators of problems recognized by the accommodation unit staff. Increasing the UMs participation and social interaction were also seen as the main way that staff had of promoting the well-being of UMs on a daily basis.

The FGDs with staff members indicated that the group model, in terms of structure and contents, seemed to align well with the staffing and structure of accommodation units, as participating staff members were both ready and willing to facilitate groups independently. This would indicate that trained non-mental health professionals are capable of providing a manualized psychological intervention when supervision is available (Ehntholt, Smith, \& Yule, 2005). However, the two individual processes proved challenging, with one process being discontinued and the other requiring more supervision to complete than the simultaneous group process.

\section{Limitations}

Motivating UMs living in the accommodation units to participate in the groups proved to be a challenge. Talking about difficult issues in a group setting was not appealing for some of the UMs, and, similar to the problems described by Ehntholt, Smith and Yule (2005), pre-existing group dynamics in the accommodation unit affected the formation of one of the groups.

The number of UMs completing the group process was small $(\mathrm{N}=18)$, limiting the generalizability of findings. The self-rated questionnaires were challenging to complete in a group setting due to difficulties with comprehension and social anxiety. In one of the units, the endline self-rated questionnaires were 
completed individually, which may be a good practice in future studies. The questions in the Brief Ethnographic Interviewing were understood and responded to in various ways by the UMs and were not systematically recorded by group facilitators. Fortunately, some of the UMs agreed to FGDs in 2018, where the importance of the social dimension of the group intervention could be confirmed.

\section{Conclusions}

In this study there was no indication that the first level of a stepped trauma care model, a group intervention based on stabilizing, had a direct impact on mental health symptoms among UMs. However, the study underlined the importance of trust building in the mental health work with this target group. Participating UMs had not been able or willing to share their difficulties prior to the intervention, even when psychiatric services had been provided, and for many of them this was the first time to express their thoughts and emotions in the host country.

Both accommodation unit staff and the UMs themselves indicated that participation and social interaction were the main indicators of problems and well-being among UMs. In line with this, it was seen that the best way for staff to promote the well-being of UMs is to promote their ability to engage with their immediate social environment and take part in daily activities of the accommodation unit. The group model can be seen as a way of promoting social interaction and building trust in the accommodation units, and through that the well-being of UMs. Further studies are required to confirm the initial impression that this kind of groups also may promote help seeking behavior among UMs, as they slowly learn to trust in adults offering to help them.

\section{Works Cited}

American Psychiatric Association. (2000). Diagnostic and statistical manual of mental disorders (4th ed., text rev.). Washington, DC. 
Bean, T., Derluyn, I., Eurelings-Bontekoe, E., Broekaert, E., \& Spinhoven, P. (2006). Validation of the multiple language versions of the Reactions of Adolescents to Traumatic Stress questionnaire. Journal of Traumatic Stress, 19(2), 241-255.

Bean, T., Eurelings-Bontekoe, E., Mooijaart, A., \& Spinhoven, P. (2006). Factors Associated with Mental Health Service Need and Utilization among Unaccompanied Refugee Adolescents. Administration and Policy in Mental Health and Mental Health Services Research, 33(3), 342355.

Cahill, S. P., Foa, E. B., Hembree, E. A., Marshall, R. D., \& Nacash, N. (2006). Dissemination of Exposure Therapy in the Treatment of Posttraumatic Stress Disorder. Journal of Traumatic Stress, 19(5), 597-610.

Clark-Kazak, C. (2012). Challenging some assumptions about 'Refugee Youth'. Forced Migration Review(40), 13-14.

Cloitre, M. (2015). The "one size fits all" approach to trauma treatment: should we be satisfied? European Journal of Psychotraumatology, 6.

Cloitre, M., Courtois, C. A., Charuvastra, A., Carapezza, R., Stolbach, B. C., \& Green, B. L. (2011). Treatment of complex PTSD: Results of the ISTSS expert clinician survey on best practices. Journal of Traumatic Stress, 615-627.

Davies, R., \& Dart, J. (2005). The 'Most Significant Change' (MSC) Technique, A Guide to Its Use, .

De Jongh, A., \& Broeke, T. (2014). Response to "Treatment compliance and effectiveness in complex PTSD patients with co-morbid personality disorder undergoing tabilizing cognitive behavioral group treatment: a preliminary study". European Journal of Psychotraumatology, 5(1).

Demazure, G., Gaultier, S., \& Pinsault, N. (2017). Dealing with difference: a scoping review of psychotherapeutic interventions with unaccompanied refugee minors. European Child \& Adolescent Psychiatry.

Derluyn, I., \& Broekaert, E. (2008). Unaccompanied refugee children and adolescents: the glaring contrast between a legal and a psychological perspective. International Journal of Law and Psychiatry, 31, 319-30.

Derluyn, I., Broekaert, E., \& Schuyten, G. (2008). Emotional and behavioural problems in migrant adolescents in Belgium. Eur Child Adolesc Psychiatry, 17, 54-62.

Dittmann, I., \& Jensen, T. K. (2014). Giving a voice to traumatized youth-Experiences with TraumaFocused Cognitive Behavioral Therapy. Child Abuse \& Neglect, 38(7), 1221-1230.

Duodecim - Finnish Medical Society. (2017). Current Care Guidlines. Retrieved 8 2017, from http://www.kaypahoito.fi/web/english/home 
Ehntholt, K. A., Smith, P. A., \& Yule, W. (2005). School-based Cognitive-Behavioural Therapy Group Intervention for Refugee Children who have Experienced War-related Trauma. Clinical Child Psychology and Psychiatry, 10(2), 235-250.

Finnish Immigration service. (2017). Turvapaikka- ja pakolaistilastot. Retrieved 8 2017, from http://www.migri.fi/tietoa_virastosta/tilastot/turvapaikka-_ja_pakolaistilasto

Finnish Immigration service. (n.d.). Children without a guardian. Retrieved 8 2017, from http://www.migri.fi/asylum_in_finland/reception_activities/reception_services/children_witho ut_a_guardian

Goodman, R. (1997). The Strengths and Difficulties Questionnaire: A Research Note. Journal of Child Psychology and Psychiatry, 38(5), 581-586.

Herman, J. (1992). Trauma and recovery. New York: Basic Books.

Hubbard, J. (2012). Manual on Brief Ethnographic Interviewing: Understanding an Issue, Problem or Idea from a Local Perspective. Retrieved 8 2017, from http://www.cvt.org/resources/researchers

IASC. (2007). Inter-Agency Standing Committee Guidelines on Mental Health and Psychosocial Support in Emergency Settings. Geneva: IASC.

ISTSS. (2017). Trauma and Mental Health in Forcibly Displaced Populations - An International Society for Traumatic Stress Studies Briefing Paper. Chicago: ISTSS.

Jensen, T. K., Holt, T., \& Ormhaug, S. M. (2017). A Follow-Up Study from a Multisite, Randomized Controlled Trial for Traumatized Children Receiving TF-CBT. Journal of Abnormal Child Psychology, 45(8), 1587-1597.

Jensen, T. K., Skårdalsmo, E. M., \& Fjermestad, K. W. (2014). Development of mental health problems - a follow-up study of unaccompanied refugee minors. Child and Adolescent Psychiatry and Mental Health, 8(1), 29.

Kangaslampi, S., Garoff, F., \& Peltonen, K. (2015). Narrative exposure therapy for immigrant children traumatized by war: study protocol for a randomized controlled trial of effectiveness and mechanisms of change. BMC Psychiatry, 15(127).

Krueger, R. A. (2002). Designing and Conducting Focus Group Interviews. University of Minnesota.

Majumder, P., O’Reilly, M., Karim, K., \& Vostanis, P. (2014). “This doctor, I not trust him, I"m not safe': The perceptions of mental health and services by unaccompanied refugee adolescents. International Journal of Social Psychiatry, 61(2), 129-136.

Michelson, D., \& Sclare, I. (2009). Psychological Needs, Service Utilization and Provision of Care in a Specialist Mental Health Clinic for Young Refugees: A Comparative Study. Clinical Child Psychology and Psychiatry,, 14(2), 273-296. 
Miller, K. E., \& Rasmussen, A. (2016). The mental health of civilians displaced by armed conflict: an ecological model of refugee distress. Epidemiology and Psychiatric Sciences, 26(02), 129-138.

Miranda, J., Bernal, G., Lau, A., Kohn, L., Hwang, \& la Fromboise, T. (2005). State of thescience on psychosocial interventions for ethnic minorities. Annual Review of Clinical Psychology, 1, 113142.

National Institute for Health and Care Excellence (NICE). (2005). Post-traumatic stress disorder: management. Retrieved 8 2017, from https://www.nice.org.uk/guidance/cg26/chapter/1Guidance

Newnham, E. A., Pearson, R. M., Stein, A., \& Betancourt, T. S. (2015). Youth mental health after civil war: The importance of daily stressors. British Journal of Psychiatry, 206(02), 116-121.

Nickerson, A., Steel, Z., Bryant, R., Brooks, R., \& Silove, D. (2010). Change in visa status amongst Mandaean refugees: Relationship to psychological symptoms and living difficulties. Psychiatry Research, 187(1-2), 267-274.

Panter-Brick, C. (2014). Health, risk, and resilience: Interdisciplinary concepts and applications. Annual Review of Anthropology, 43, 431-448.

Perrin, S., Meiser-Stedman, R., \& Smith, P. (2005). The Children's Revised Impact of Event Scale (CRIES): Validity as a Screening Instrument for PTSD. Behavioural and Cognitive Psychotherapy, 33(4), 487.

Pottie, K., Greenaway, C., Feightner, J., Welch, V., Swinkels, H., Rashid, M., et al. (2011). Evidence-based clinical guidelines for immigrants and refugees. CMAJ(12).

R Core Team. (2016). R: A language and environment for statistical computing. Vienna, Austria: $R$ Foundation for Statistical Computing.

Renner, W. (2009). The effectiveness of psychotherapy with refugees and asylum seekers: A preliminary results from an Austrian study. Journal of Immigrant and Minority Health, 11, 41-45.

Sanchez-Cao, E., Kramer, T., \& Hodes, M. (2012). Psychological distress and mental health service contact of unaccompanied asylum-seeking children. Child: Care, Health and Development, 39(5), 651-659.

Sarkadi, A., Ådahl, K., Stenvall, E., Ssegonja, R., Batti, H., Gavra, P., et al. (2017). Teaching Recovery Techniques: evaluation of a group intervention for unaccompanied refugee minors with symptoms of PTSD in Sweden. European Child \& Adolescent Psychiatry.

Slobodin, O., \& de Jong, J. T. (2015). Mental health interventions for traumatized asylum seekers and refugees: What do we know about their efficacy? International Journal of Social Psychiatry, 61(1), 17-26. 
Smith, P., Perrin, S., Dyregrov, A., \& Yule, W. (2003). Principal components analysis of the Impact of Event Scale with children in war. Personality and Individual Differences, 34(2), 315-22.

Sourander, A. (1998). Behavior problems and traumatic events of unaccompanied refugee minors. Child Abuse \& Neglect, 22(7), 719-727.

Ungar, M., \& Liebenberg, L. (2011). Assessing resilience across cultures using mixed methods: Construction of the child and youth resilience measure. Journal of Mixed Methods Research, 5, 126-149.

UNHCR. (1994). Refugee children. Guidelines on protection and care. Geneva: United Nations High Commissioner for Refugees.

Van Minnen, A., Harned, M. S., Zoellner, L., \& Mills, K. (2012). Examining potential contraindications for prolonged exposure therapy for PTSD. European Journal of Psychotraumatology, 3.

Vervliet, M., Rousseau, C., Broekaert, E., \& Derluyn, I. (2015). Multilayered Ethics in Research Involving Unaccompanied Refugee Minors. Journal of Refugee Studies, 28(4), 468-485. 